\title{
Prevalência de queixas osteomusculares e fadiga em docentes de uma universidade em Santarém - Pará
}

\author{
Prevalence of osteomuscular and fatigue complaints in teachers at a university in \\ Santarém - Pará
}

Prevalencia de quejas osteomusculares y fatiga en profesores de una universidad de Santarém - Pará

Adenilza Lima Alves ${ }^{1}$, Camila Guimarães de Jesus ${ }^{1}$, Erica Caroline Azevedo Pereira ${ }^{1 *}$, Melina Laíse Nascimento dos Santos ${ }^{1}$.

\section{RESUMO}

Objetivo: Analisar a prevalência de queixas osteomusculares e fadiga em docentes de uma universidade na cidade de Santarém-Pará. Métodos: Realizou-se uma pesquisa observacional, quantitativa, qualitativa, descritiva e transversal, a qual utilizou como instrumentos de coleta de dados o Questionário Nórdico de Sintomas Osteomusculares (QNSO), a Escala de Fadiga de Chalder (CFQ-11) e um Questionário Sociodemográfico. A amostra foi composta por trinta e um $(n=31)$ docentes, $(n=12$ do sexo masculino e $n=19$ do feminino), de uma Instituição de Ensino Superior (IES). Resultados: Houve prevalência de 93,55\% de queixas osteomusculares para região lombar e $77,42 \%$ para as regiões de pescoço/cervical e dorsal nos últimos 12 meses. Nos últimos 7 dias, a prevalência de sintomas foi de $96,77 \%$ dentre os participantes, com $22,58 \%$ para região lombar. Dentre os impedidos de realizar suas atividades normais, $70,97 \%$ queixam-se de desconfortos lombares. Em relação ao CFQ-11, três participantes $(9,67 \%)$ apresentaram quadro de fadiga geral. Quanto à fadiga física, 35,48\% $(n=11)$ da amostra pontuaram valores de 4 à 6 pontos e 3,22\% $(n=1)$ apresentaram sintomas de fadiga mental. Conclusão: Elevada prevalência de queixas osteomusculares nos últimos 7 dias. Sintomatologia dolorosa predominante sobre região lombar. Observa-se baixo índice de fadiga mental e física entre os participantes do estudo.

Palavras-chave: Queixas osteomusculares, Fadiga, Docentes.

\begin{abstract}
Objective: To analyze the prevalence of musculoskeletal complaints and fatigue among professors at a university in the city of Santarém-Pará. Methods: An observational, quantitative, qualitative, descriptive and cross-sectional research was carried out, which used the Nordic Musculoskeletal Questionnaire (QNSO), the CFQ-11 (Chalder Fatigue Scale) and a Questionnaire as data collection instruments. Sociodemographic. The sample consisted of thirty-one $(n=31)$ teachers, $(n=12$ male and $n=19$ female), from a Higher Education Institution (HEI). Results: There was a prevalence of $93.55 \%$ of musculoskeletal complaints for the lumbar region and $77.42 \%$ for the neck / cervical and dorsal regions in the last 12 months. In the last 7 days, the prevalence of symptoms was $96.77 \%$ among the participants, with $22.58 \%$ for the lumbar region. Among those prevented from performing their normal activities, $70.97 \%$ complain of lumbar discomfort. In relation to the CFQ-11, three participants (9.67\%) presented a general fatigue picture. As for physical fatigue, $35.48 \%(\mathrm{n}=$ 11) of the sample scored values from 4 to 6 points and $3.22 \%(n=1)$ showed symptoms of mental fatigue. Conclusion: High prevalence of musculoskeletal complaints in the last 7 days. Pain symptoms predominant over the lumbar region. There is a low rate of mental and physical fatigue among the study participants.
\end{abstract}

Keywords: Musculoskeletal complaints, Fatigue, Teachers.

\section{RESUMEN}

Objetivo: Analizar la prevalencia de quejas musculoesqueléticas y fatiga entre profesores de una universidad de la ciudad de Santarém-Pará. Métodos: Se realizó una investigación observacional, cuantitativa, cualitativa, descriptiva y transversal, que utilizó como instrumentos de recolección de datos el Cuestionario Nórdico

${ }^{1}$ Instituto Esperança de Ensino Superior (IESPES), Santarém - PA. *E-mail: carolerica96@gmail.com 
Musculoesquelético (QNSO), el Escala de Fatiga de Chalder (CFQ-11) y un Cuestionario Sociodemográfico. La muestra estuvo conformada por treinta y un $(n=31)$ docentes, $(n=12$ hombres yn $=19$ mujeres), de una Institución de Educación Superior (IES). Resultados: Hubo una prevalencia de $93,55 \%$ de quejas musculoesqueléticas para la región lumbar y $77,42 \%$ para las regiones cervical y dorsal en los últimos 12 meses. En los últimos 7 días, la prevalencia de síntomas fue del $96,77 \%$ entre los participantes, con un $22,58 \%$ para la región lumbar. Entre los impedidos de realizar sus actividades habituales, el $70,97 \%$ se queja de molestias lumbares. En relación al CFQ-11, tres participantes $(9,67 \%)$ presentaron un cuadro de fatiga general. En cuanto a la fatiga física, el $35,48 \%(n=11)$ de la muestra puntuó valores de 4 a 6 puntos y el $3,22 \%(n=1)$ presentó síntomas de fatiga mental. Conclusión: Alta prevalencia de quejas musculoesqueléticas en los últimos 7 días. Los síntomas de dolor predominan sobre la región lumbar. Existe una baja tasa de fatiga mental y física entre los participantes del estudio.

Palabras clave: Quejas musculoesqueléticas, Fatiga, Maestros.

\section{INTRODUÇÃO}

A docência é uma atividade complexa, seu exercício exige múltiplos saberes, pois a educação, independentemente do nível de ensino que aconteça, é uma ação humana que demanda da capacidade física e mental do trabalhador, podendo acarretar em problemas de saúde e comprometer a qualidade de vida. Com base nessa colocação, à docência é uma área que apresenta diferentes exigências e dimensões de cuidado, aprendizado e ensino que estão relacionados a conteúdos cognitivos, efetivos e instrumentais que demandam muito do profissional (VALLE G, 2017; CAMPOS T, 2017).

As investigações sobre trabalho docente e saúde no Brasil floresceram a partir da década de 1990, quando foram gestadas as primeiras pesquisas com foco na produção de conhecimento sobre a saúde de professoras e professores. Em 2015 o Congresso Nacional de Educação registrou o déficit nacional de professores em educação básica no Brasil, e identificou que $66 \%$ desses profissionais, já precisaram se afastar do trabalho por questões de saúde (SANTOS A, 2015).

No Brasil, as principais manifestações clínicas relacionadas ao trabalho são as denominadas de lesões por esforços repetitivos (LER) ou distúrbios osteomusculares relacionados ao trabalho (DORT). Surgem devido extensas jornadas de trabalho, acompanhadas de movimentos repetitivos, manutenção de posturas inadequadas e emprego excessivo de força. O desenvolvimento de distúrbios decorrentes do sistema musculoesquelético pode levar ao aparecimento de diversos sinais e sintomas como a dor e incapacidade funcional. Os professores são a segunda categoria profissional mais acometida por doenças ocupacionais em nível mundial. Além disso, a atividade exercida por eles é considerada pela organização internacional do trabalho (OIT) como uma atividade de risco desde 1981 (FERNANDES GCPS, 2018).

A relação entre os aspectos psicossociais do trabalho e os sintomas osteomusculares são estudados em várias profissões. É reconhecido que algumas categorias profissionais são mais expostas ao surgimento desses sintomas. Fatores psicossociais de trabalho são apontados, há muitos anos, por estarem relacionados a várias queixas de saúde. O estresse ocupacional também pode afetar e propiciar a prevalência de distúrbios e sintomas musculoesqueléticas (ALMEIDA LMDS e DUMITH SDC, 2018).

Os distúrbios decorrentes do sistema musculoesquelético podem levar ao aparecimento de diversas sintomatologias causadas por lesões que repercutem para fora do ambiente laboral, gerando uma sobrecarga ao docente, que acumula tanto deveres profissionais, quanto pessoais. Dores musculares e cansaço físico, podem ser caracterizados como fadiga proveniente da rotina do educador, o que pode gerar um comprometimento da saúde mental do professor, afetando diretamente o seu rendimento na área educacional, independentemente do nível de ensino e instituição que leciona (SILVA EB, et al., 2015).

No tratamento é importante a participação de médicos, enfermeiros, fisioterapeutas, terapeutas ocupacionais e psicólogos. Dessa forma orientar, instrumentalizar e informar o paciente de sua condição para que ele aprenda a administrar sua vida, limites, conflitos e realizar o melhor tratamento. Nas crises agudas de dor, o tratamento inclui o uso de anti-inflamatórios e repouso das estruturas musculoesqueléticas comprometidas. Nas fases mais avançadas da síndrome, a aplicação de corticoides na área da lesão ou por via oral e fisioterapia (NICOLETTI S, 2017). 
Diante disso, seria de grande importância a inserção da fisioterapia na saúde desses trabalhadores, pois, sua atuação visa melhorar a qualidade de vida e prevenir lesões músculo esqueléticas. O resultado desta intervenção é uma melhora no desempenho e na produtividade no trabalho. Os exercícios mais utilizados pelos autores no tratamento desses sintomas foram baseados em técnicas de auto alongamento, fortalecimento muscular, mobilização articular ativa, facilitação neuromuscular proprioceptiva, reeducação postural e exercícios respiratórios. A fim de padronizar duas intervenções, individuais e em grupo (DA SILVA MAIA FE, 2014; BARBOSA LGA, 2017).

Este estudo foi desenvolvido com o objetivo central de analisar a prevalência de queixas osteomusculares e fadiga em docentes de uma universidade na cidade de Santarém-Pará, a fim de investigar os possíveis fatores que contribuam para 0 aparecimento de sintomas musculoesqueléticos nessa classe, fornecer subsídios estatísticos sobre a saúde ocupacional docente no intuito de futuramente, por meio desses dados, contribuir para a implementação de medidas preventivas em saúde para esses profissionais produzindo informações úteis no campo da pesquisa epidemiológica.

\section{MÉTODOS}

De acordo com informações fornecidas pelo setor de Recursos Humanos da IES, há 125 docentes atuando na mesma, que de acordo com a disponibilidade dos participantes, possibilitou uma amostra total de 31 docentes universitários para este estudo. Todos os participantes contribuíram com a pesquisa e preencheram os critérios de inclusão, dessa forma, não houve perdas na amostra do estudo e os mesmos assinaram o Termo de Consentimento Livre e Esclarecido (TCLE).

Após parecer favorável do Comitê de Ética em Pesquisa com Seres Humanos (CEP) № 3.557.620, foi iniciada a coleta dos dados. Os docentes foram abordados da seguinte forma: através de convites elaborados pelos próprios pesquisadores e fixados na IES, onde além de detalhes sobre a pesquisa, constava o número de telefone e endereço de e-mail, sendo que por meio destes, o docente deveria manifestar voluntariamente seu interesse em participar da pesquisa, informando sua disponibilidade de data e horário. Após agendamento prévio, os questionários foram aplicados individualmente em uma sala privativa.

Foram seguidas e mantidas as medidas de segurança contra o novo coronavírus, como distanciamento social, higienização das mãos com álcool em gel 70\%, uso obrigatório de máscara e o não compartilhamento de objetos pessoais necessários para o preenchimento dos questionários.

A coleta de dados ocorreu entre os meses de setembro e outubro de 2019 a agosto e novembro de 2020 , nos turnos matutino e vespertino. Foram aplicados três questionários, sendo eles: Questionário Sociodemográfico, Questionário Nórdico de Sintomas Osteomusculares (QNSO) e Questionário de Fadiga de Chalder (CFQ-11). Os pesquisadores receberam um treinamento prévio para a coleta de dados, de modo a sanar possíveis vieses e confusão na interpretação dos questionários aplicados.

O questionário Sociodemográfico continha perguntas relacionadas as informações gerais (gênero, idade, estado civil, número de filhos) e informações ocupacionais (tempo de atuação profissional, turno em que trabalha, número de classes, carga horária semanal) para a caracterização do estilo de vida e perfil profissional de cada participante, respectivamente.

Para avaliar a prevalência de sintomas osteomusculares foi aplicado o QNSO, que consiste em uma imagem na qual estão destacadas e numeradas regiões do corpo, que servirão como base para que o participante registre a frequência em que tenha sentido dor, dormência, formigamento ou desconforto. Os índices da frequência são numerados de 0 a 3 , sendo (0) não, (1) raramente, (2) com frequência e (3) sempre. Podendo o participante assinalar apenas uma opção.

Por fim, foi utilizado o terceiro questionário, a Escala de Fadiga de Chalder, que consiste em perguntas relacionadas a sintomas físicos e mentais, no qual o participante irá registrar a frequência que apresentou problemas de cansaço, fraqueza ou falta de energia no último mês. Os índices da frequência são numerados de 1 a 4, sendo (1) não/menos do que o normal, (2) igual ao normal, (3) mais que o normal e (4) muito mais que o normal. 
Acerca das análises dos dados, os mesmos foram avaliados de forma descritiva utilizando o programa Excel (Microsoft for Windows, versão 2013) para o armazenamento das informações e a realização dos cálculos.

\section{RESULTADOS}

As informações do perfil sociodemográfico dos docentes mostrou a média de idade de $34,32 \pm 6,04$ anos, variando entre 26 e 52 anos. Compuseram a amostra da pesquisa participantes de ambos os gêneros, sendo $n=19$ do gênero feminino e $n=12$ do gênero masculino.

Em relação ao estado civil foi observado que a maioria dos docentes eram casados (64,52\%). Apenas um professor possuía três filhos, a maioria da amostra, com 35,48\% dos professores, não possuía nenhum filho e $61,29 \%$ possuía dois ou apenas um. Ressaltamos que, $38,71 \%$ dos docentes relataram realizar trabalhos extraclasse todos os dias.

A maioria dos docentes demonstraram estar satisfeitos com seu trabalho, o quantitativo de quatro participantes expressou desejo em mudar de área de atuação e vinte e seis professores mantém atividade ocupacional secundária à docência. As demais características sociodemográficas estão expressas na Tabela 1.

Tabela 1 - Distribuição das características quanto à titulação, tempo de atuação profissional, turno em que trabalha, número de classes que leciona, carga horária semanal e realização de trabalhos extraclasse entre os docentes ( $n=31)$ de uma IES, Santarém, Pará, 2021.

\begin{tabular}{lcc}
\hline Características & $\mathbf{N}$ & $\%$ \\
\hline Titulação & 17 & $54,84 \%$ \\
\hline Especialização & 13 & $41,94 \%$ \\
Mestrado & 1 & $3,23 \%$ \\
Especialização e mestrado & & \\
\hline Tempo de atuação profissional (anos) & 24 & $77,42 \%$ \\
\hline$\leq 10$ & 7 & $22,58 \%$ \\
$\geq 11$ & & \\
\hline Turno em que trabalha & 13 & $41,94 \%$ \\
\hline Matutino, vespertino e noturno & 1 & $3,23 \%$ \\
Vespertino & 11 & $35,48 \%$ \\
Vespertino e noturno & 4 & $12,90 \%$ \\
Noturno & 2 & $6,45 \%$ \\
Matutino e Noturno & & \\
\hline $\mathbf{N}^{\circ}$ de classes & 2 & $6,45 \%$ \\
\hline 1 & 5 & $16,13 \%$ \\
2 & 1 & $3,23 \%$ \\
3 & 9 & $6,03 \%$ \\
4 & 2 & $16,13 \%$ \\
5 & 5 & $9,68 \%$ \\
6 & 3 & $6,45 \%$ \\
7 & 2 & $3,23 \%$ \\
8 & 1 & $3,23 \%$ \\
9 & 1 & $38,71 \%$ \\
11 & 12 & $3,23 \%$ \\
\hline Trabalho Extraclasse & 6 &
\end{tabular}

Fonte: Alves AL, et al., 2021. 
Na Tabela 2 temos a distribuição das características, quanto à realização, frequência e duração de atividade física. Destaca-se que apenas $48,39 \%$ desses docentes realizam atividades físicas, sendo que a maioria, 33,33\%, faz musculação.

Tabela 2 - Distribuição das características quanto à realização, frequência e duração de atividade física pelos docentes $(n=31)$ de uma IES, Santarém, Pará, 2021.

\begin{tabular}{|c|c|c|}
\hline Características & $\mathbf{N}$ & $\%$ \\
\hline \multicolumn{3}{|c|}{ Realiza atividade física } \\
\hline Não & 16 & $51,61 \%$ \\
\hline Sim & 15 & $48,39 \%$ \\
\hline \multicolumn{3}{|l|}{ Qual? ( $n=15)$} \\
\hline Caminhada & 3 & $20 \%$ \\
\hline Musculação & 5 & $33,33 \%$ \\
\hline Musculação e outros & 3 & $20 \%$ \\
\hline Outros & 4 & $26,67 \%$ \\
\hline \multicolumn{3}{|c|}{ Frequência que realiza a atividade física - vezes por semana $(n=15)$} \\
\hline 1 & 1 & $6,67 \%$ \\
\hline 2 & 5 & $33,33 \%$ \\
\hline $3 \mathrm{ou}+$ & 9 & $60 \%$ \\
\hline \multicolumn{3}{|c|}{ Duração da atividade física $(n=15)$} \\
\hline 30 minutos & 2 & $13,33 \%$ \\
\hline 60 minutos & 13 & $86,67 \%$ \\
\hline
\end{tabular}

Fonte: Alves AL, et al., 2021.

Os dados obtidos por meio do QNSO mostram que os sintomas osteomusculares que mais os impediram de realizar suas atividades normais foram na região do pescoço/cervical $(58,06 \%)$ e na região lombar (70,97\%), como mostra na Tabela 3.

Tabela 3 - Distribuição dos sintomas osteomusculares e incapacidade funcional entre os docentes $(n=31)$ de uma IES, Santarém, Pará, 2021.

\begin{tabular}{cccc}
\hline Região & $\begin{array}{c}\text { Sintomas } \\
\text { nos últimos } \\
\mathbf{1 2} \text { meses (\%) }\end{array}$ & $\begin{array}{c}\text { Sintomas nos } \\
\text { últimos 7 dias(\%) }\end{array}$ & $\begin{array}{c}\text { Impedimento de realizar atividades } \\
\text { normais por causa deste problema } \\
\text { nos últimos 12 meses (\%) }\end{array}$ \\
\hline Pescoço/Região cervical & 77,42 & 12,90 & 58,06 \\
\hline Ombros & 74,19 & 3,23 & 45,16 \\
\hline Braços & 51,61 & 6,45 & 22,58 \\
\hline Cotovelos & 22,58 & - & 9,68 \\
\hline Antebraços & 38,71 & - & 19,35 \\
\hline Punhos/Mãos/Dedos & 64,52 & 9,68 & 48,39 \\
\hline Região dorsal & 77,42 & 6,45 & 51,61 \\
\hline Região lombar & 93,55 & 22,58 & 70,97 \\
\hline Quadril/Membros inferiores & 61,29 & 3,23 & 41,94 \\
\hline
\end{tabular}

Fonte: Alves AL, et al., 2021.

Nas Tabelas 4 e 5 temos a distribuição de sintomas osteomusculares relacionados a frequência de dor, dormência, formigamento ou desconforto nos últimos doze meses e últimos sete dias, respectivamente. 
Tabela 4 - Distribuição de sintomas osteomusculares, considerando os últimos 12 meses, entre os docentes $(n=31)$ de uma IES, Santarém, Pará, 2021.

\begin{tabular}{lcccccccc}
\hline \multirow{2}{*}{\multicolumn{1}{c}{ Região }} & \multicolumn{3}{c}{$\mathbf{0}$} & \multicolumn{1}{c}{$\mathbf{1}$} & \multicolumn{2}{c}{$\mathbf{2}$} & $\mathbf{3}$ \\
\cline { 2 - 9 } & $\mathbf{n}$ & $\%$ & $\mathbf{n}$ & $\%$ & $\mathbf{n}$ & $\%$ & $\mathbf{n}$ & $\%$ \\
\hline Pescoço / Região Cervical & 7 & $22,6 \%$ & 9 & $29 \%$ & 12 & $38,7 \%$ & 3 & $9,7 \%$ \\
Ombros & 8 & $25,8 \%$ & 9 & $29 \%$ & 12 & $38,7 \%$ & 2 & $6,5 \%$ \\
Braços & 15 & $48,4 \%$ & 9 & $29 \%$ & 5 & $16,1 \%$ & 2 & $6,5 \%$ \\
Cotovelos & 24 & $77,4 \%$ & 5 & $16,1 \%$ & 1 & $3,2 \%$ & 1 & $3,2 \%$ \\
Antebraços & 19 & $61,3 \%$ & 10 & $32,3 \%$ & 1 & $3,2 \%$ & 1 & $3,2 \%$ \\
Punhos / Mãos / Dedos & 11 & $35,5 \%$ & 10 & $32,3 \%$ & 6 & $19,4 \%$ & 4 & $12,9 \%$ \\
Região Dorsal & 7 & $22,6 \%$ & 8 & $25,8 \%$ & 8 & $25,8 \%$ & 8 & $25,8 \%$ \\
Região Lombar & 2 & $6,5 \%$ & 6 & $19,4 \%$ & 13 & $41.9 \%$ & 10 & $32,3 \%$ \\
Quadril / Membros Inferiores & 12 & $38,7 \%$ & 11 & $35,5 \%$ & 5 & $16,1 \%$ & 3 & $9,7 \%$ \\
\hline
\end{tabular}

Fonte: Alves AL, et al., 2021.

É importante salientar que, nos últimos 12 meses, os sintomas osteomusculares prevaleceram em 35,5\% para quadril e membros inferiores ( $1=$ raramente); $41,9 \%$ para região lombar ( $2=$ com frequência) e 32,3\% também para região lombar $(3=$ sempre $)$.

Tabela 5 - Distribuição de sintomas osteomusculares, considerando os últimos 7 dias, entre os docentes $\underline{(\mathrm{n}=31) \text { de uma IES, Santarém, Pará, } 2021 .}$

\begin{tabular}{lllllllll}
\hline \multirow{2}{*}{ Região } & $\mathbf{0}$ & \multicolumn{3}{c}{$\mathbf{1}$} & \multicolumn{3}{c}{$\mathbf{2}$} & $\mathbf{3}$ \\
\cline { 2 - 9 } & $\mathbf{n}$ & $\%$ & $\mathbf{n}$ & $\%$ & $\mathbf{n}$ & $\%$ & $\mathbf{n}$ & $\%$ \\
\hline Pescoço / Região Cervical & 13 & $41,9 \%$ & 8 & $25,8 \%$ & 7 & $22,6 \%$ & 3 & $9,7 \%$ \\
Ombros & 17 & $54,8 \%$ & 3 & $9,7 \%$ & 7 & $22,6 \%$ & 4 & $12,9 \%$ \\
Braços & 24 & $77,4 \%$ & 3 & 9,7 & 2 & $6,5 \%$ & 2 & $6,5 \%$ \\
Cotovelos & 28 & $90,3 \%$ & 1 & $3,2 \%$ & 2 & $6,5 \%$ & - & - \\
Antebraços & 25 & $80,6 \%$ & 4 & $12,9 \%$ & 2 & $6,5 \%$ & - & - \\
Punhos / Mãos / Dedos & 16 & $51,6 \%$ & 9 & $29 \%$ & 4 & $12,9 \%$ & 2 & $6,5 \%$ \\
Região Dorsal & 15 & $48,4 \%$ & 8 & $25,8 \%$ & 5 & $16,1 \%$ & 3 & $9,7 \%$ \\
Região Lombar & 9 & $29 \%$ & 8 & $25,8 \%$ & 9 & $29 \%$ & 5 & $16,1 \%$ \\
Quadril / Membros Inferiores & 18 & $58,1 \%$ & 8 & $25,8 \%$ & 3 & $9,7 \%$ & 2 & $6,5 \%$ \\
\hline
\end{tabular}

Fonte: Alves AL, et al., 2021.

Considerando as queixas osteomusculares dos últimos 7 dias, 96,77\% da amostra apresentou alguma dor, desconforto ou formigamento. Dentre as que prevaleceram, é importante frisar a frequência de $29 \%$ para punhos, mãos e dedos ( 1 = raramente), $29 \%$ para região lombar ( 2 =com frequência) e $16,1 \%$ também para região lombar ( 3 = sempre).

Na Tabela 6 contém a média de pontos obtidos através da Escala de Fadiga de Chalder. A fadiga física é analisada por sete questões do CFC-11 e a mental por 4. Para cada resposta do participante ele pontua 0 ou 1 por questão, ao final, soma-se a pontuação e define-se a presença ou ausência de fadiga geral, física ou mental. As pontuações de referência que determinam a presença desses sintomas vão de 8 a 11 para fadiga geral, 4 a 7 fadiga física e 4 para fadiga mental. Dessa forma, três participantes apresentaram quadro de fadiga geral, 11 de fadiga física e, apenas, 1 apresentou sintomas de fadiga mental. 
Tabela 6 - Dados descritivos quanto à pontuação na Escala de Fadiga de Chalder entre docentes $(n=31)$ de uma IES, Santarém, Pará, 2021.

\begin{tabular}{lccc}
\hline Dados & Sintomas físicos & Sintomas mentais & Fadiga Geral \\
\hline Média & 2,52 & 0,71 & 3,23 \\
DP & 2,23 & 0,73 & 2,84 \\
\hline
\end{tabular}

Legenda: $\mathrm{DP}=$ Desvio padrão.

Fonte: Alves AL, et al., 2021.

Dos docentes que afirmaram praticar atividade física, um percentual de $20 \%(n=3)$ apresentou sintomas de fadiga de acordo com o somatório da pontuação obtida através do Questionário de Fadiga de Chalder. Dos três docentes, o primeiro apresentou sintomas de fadiga física, já o segundo, sintomas de fadiga física, mental e geral, e o terceiro, sintomas de fadiga física e geral.

\section{DISCUSSÃO}

Este estudo tem como amostra, em sua maioria, docentes do sexo feminino, com média de idade entre 26 e 52 anos. Diferentemente do achado encontrado no estudo de Calixto MF, et al. (2015), que pesquisa a prevalência de sintomas osteomusculares e suas relações com o desempenho ocupacional entre professores do ensino médio público, onde a amostra do mesmo foi composta em sua maioria por professores do sexo masculino, com média de idade de 40 anos. Porém, a maioria dos estudos indicam que as mulheres estão inseridas em maior número nesse meio, por estarem dominando gradualmente o mercado de trabalho. (SILVA JVC, et al. 2019).

De acordo com Mango MSM (2012), repassar conhecimento é uma tarefa que pode ser muito estressante, que gera alterações evidentes na saúde mental, física e até mesmo no desenvolvimento profissional e pessoal dos docentes. Isto ocorre em professores através do estresse ocupacional percebido pelos sintomas e diminuição da presença no trabalho. Somado aos problemas físicos, estes profissionais também podem apresentar fatores psicológicos, dentre eles a irritabilidade, ansiedade, hostilidade, depressão e abatimento emocional.

Cargas horárias excessivas de trabalho, implicam de maneira direta na saúde do trabalhador, dentre os docentes participantes da pesquisa, cerca de $41,94 \%$ possuem carga horária de trabalho $\geq$ a 40 horas semanais na instituição de ensino em questão. Contrapondo ao estudo de Fernandes $\mathrm{MH}$, et al. (2011), que trata do Impacto da sintomatologia osteomuscular na qualidade de vida de professores da rede pública municipal de Natal/RN, onde a média da carga horária semanal de trabalho foi de 32 horas.

No quesito atividade secundária, neste estudo 26 docentes $(n=31)$, afirmaram manter outra atividade além da docência. Resultado distinto ao do estudo de Borges LCDC, et al. (2019), que teve como objetivo, identificar os fatores ocupacionais associados à dores musculoesqueléticas dos professores do ensino básico e médio da cidade de Edéia-GO, onde 45 participantes da pesquisa $(n=50)$, declararão não desenvolver outra atividade além da docência. Quanto ao turno de trabalho, um quantitativo de 16, 13\% da amostra leciona em apenas um turno. Número inferior ao do estudo de Borges LCDC, et al. (2019), no qual 38\% dos participantes desenvolviam a sua atividade me apenas um turno de trabalho.

Em se tratando de trabalho extraclasse, no estudo de Branco JC, et al. (2017) em que trata da prevalência de sintomas osteomusculares em professores da rede pública e privada do ensino fundamental, cerca $74,1 \%$ dos docentes realizavam atividade extraclasse todos os dias, já esta pesquisa, apresenta um número inferior ao citado anteriormente, o quantitativo de $38,71 \%$ dos participantes da pesquisa afirmou realizar trabalhos extraclasse todos os dias. Essa associação nos leva a inferir que o nível de escolaridade em que o professor leciona, irá determinar o seu tempo destinado a atividades extraclasses.

De acordo com Branco JC, et al. (2017), as longas jornadas de trabalho estão relacionadas a diminuição ou ausência da prática de atividade física por falta de tempo livre. Os docentes se submetem a maior sobrecarga de trabalho em busca de uma melhor remuneração, em contrapartida, tem se tornado sedentário 
e contribuído para a manifestação de incapacidades funcionais. Relacionado a prática de atividade física, a pesquisa de Mango MSM, et al. (2012), que investiga a análise dos sintomas osteomusculares de professores do ensino fundamental, no que tange à atividade física, 55,5\% relataram a prática de atividade física, já os $44,4 \%$ restantes não praticavam nenhum tipo de atividade, enquanto na nossa pesquisa apenas 15 docentes $(48,39 \%)$ disseram que realizam atividade física e os que relataram não praticar foram 16 docentes $(51,61 \%)$. Ou seja, podemos notar que as pesquisas se divergem, pois, na de Mango MSM, et al. (2012), notou-se maior adesão a prática de atividades físicas por parte dos docentes, enquanto nesta pesquisa os docentes demonstraram ser mais sedentários.

Fernandes CS, et al. (2018) afirma que a posição adotada pelos professores em pé no decorrer da sua rotina de trabalho, pode influenciar nas desordens musculares em alguma região do corpo. De acordo com Suda EY, et al. (2011), altos índices de sintomas osteomusculares que os docentes apresentam são decorrentes da exaustão física e emocional que esses profissionais retratam. Os docentes podem apresentar dificuldades ou até mesmo serem impedidos de realizar atividades dentro e fora da sala de aula pela presença de sintomas osteomusculares ou por possuírem LER/DORT, dessa forma diminuindo sua capacidade funcional e aumentando o risco ocupacional.

Nesta pesquisa, a média de sintomas osteomusculares que a amostra apresentou nos últimos doze meses foi de $62,37 \%$, corroborando com outros estudos que encontraram altos índices de sintomas osteomusculares em docentes da educação básica, com a média variando entre $48 \%$ a 58\% (ROCHA RER, et al. 2017). Os resultados encontrados mostram que as maiores queixas osteomusculares nos últimos 12 meses foram nas regiões de pescoço/cervical, dorsal e lombar, e, as menos acometidas são, cotovelos, antebraços e braços, semelhantes a estudos anteriores, onde as regiões mais acometidas são pescoço e região dorsal e as outras regiões de menor acometimento são cotovelos, quadril e/ou coxas e joelhos (SILVA CC e NEVES MDS, 2018).

Com relação as queixas osteomusculares nos últimos sete dias, 96,77\% da amostra apresentaram algum tipo de dor, formigamento ou dormência, sendo que a região de punho /mãos/dedos e região lombar obtiveram $29 \%$ e região lombar $16,1 \%$, porém, quando comparado com o estudo de Silva JVC, et al. (2019), os dados se divergem, pois, a região com maior prevalência de queixas osteomusculares foi o ombro com $41,74 \%$.

Após a análise feita no estudo de Campos ALP, et al., (2016), que tratava da prevalência de sintomas osteomusculares em indivíduos ativos e sedentários, verificou-se que em uma amostra composta por 49 participantes, cerca de 59,18\% ( $n=29)$ eram fisicamente ativos, quando relacionados com sintomas osteomusculares nos últimos 7 dias, cerca de $25 \%$ do grupo ativo, relatou a presença desses sintomas neste período. Ao fazer uma comparação com os indivíduos sedentários da presente pesquisa, podemos observar que esses indivíduos totalizaram cerca $48,39 \%$ de uma amostra de 31 participantes, além disso, em relação a presença de sintomas osteomusculares nos últimos 7 dias, todos referiram sintomas neste período. No comparativo entre as duas pesquisas, é perceptível que há uma menor prevalência de sintomas osteomusculares em indivíduos fisicamente ativos.

Nas correlações sobre o aspecto fadiga, no estudo de De Sousa MNA, et al. (2017) que abrangeu uma amostra de 38 participantes e teve como objetivo mensurar os níveis de estresse e fadiga entre trabalhadores de limpeza urbana, cerca de $36,8 \%$ dos participantes apresentaram sintomas de fadiga, já de acordo com os dados desta pesquisa, é possível perceber um quantitativo maior de participantes com sintomas de fadiga, cerca de $48,39 \%$ do total da amostra $(n=31)$. A partir desta análise pode-se perceber que o tipo de atividade exercida poderá interferir na presença ou ausência de sintomas de fadiga e seus níveis, além de que trabalhos que demandam cargas físicas, mentais e emocionais, tendem a registrarem maiores números em relação a esses sintomas.

Dessa forma, a abordagem fisioterapêutica seria de suma importância, pois, abrange tanto a prevenção quanto, a manutenção e o restabelecimento da saúde do trabalhador. Agindo por meio do enfoque em aspectos biomecânicos, ergonômicos, além de exercícios laborais, sempre levando em consideração os aspectos individuais de cada trabalhador, promovendo desta forma, intervenções mais adequadas às necessidades dessa classe (BOSI PL, 2018). 
A fisioterapia é na maioria das vezes a primeira e única técnica terapêutica convencional acessível e pode ser um procedimento de longa duração na vida destes profissionais. A aplicação de recursos físicos como cinesioterapia, acupuntura, laser, entre outros, é imprescindível para o domínio dos sintomas osteomusculares (SILVA LPDS e MORSCH P, 2019).

Porém, é real a necessidade da elaboração de planos de ação que tenham como objetivo, facilitar o acesso dessa categoria de profissionais a intervenções fisioterapêuticas, tanto em ambiente interno de trabalho, quanto externamente, onde além do atendimento realizado pelo fisioterapeuta, também sejam oferecidos acompanhamentos por outros profissionais, dessa forma, promovendo o cuidado multiprofissional e proporcionando uma melhor qualidade de vida a esses profissionais (MEIRA CJ, et al., 2018).

\section{CONCLUSÃO}

Apesar das limitações amostrais do estudo, os dados apresentados são relevantes, uma vez que pôde-se investigar as prevalências de sintomas osteomusculares e de fadiga nos docentes universitários, dessa forma, sugere-se estudos mais robustos que refutem ou confirmem os dados, de forma a subsidiar medidas que previnam o adoecimento desses profissionais. Além disso, se mostra necessária a inclusão do enfoque nas abordagens fisioterapêuticas voltadas para este público, o que permitirá mensurar de que forma a fisioterapia irá exercer influência na prevenção e diminuição desses sintomas.

\section{REFERÊNCIAS}

1. ATAIDE PC, NUNES IML. Feminização da Profissão Docente: as representações das professoras sobre a relação entre ser mulher e ser professora do ensino fundamental. Revista Educação e Emancipação, 2016; p. 167-188.

2. ALMEIDA LMDS, DUMITH SDC. Associação entre sintomas osteomusculares e estresse percebido em servidores públicos de uma Universidade Federal do Sul do Brasil. BrJP, 2018; 1(1): 9-14.

3. BARBOSA LGA. Fisioterapia preventiva nos distúrbios osteomusculares relacionados ao trabalho - DORT: a fisioterapia do trabalho aplicada. Rio de Janeiro: Guanabara Koogan; 2017.

4. BRANCO JC, et al. Prevalência de sintomas osteomusculares em professores de escolas públicas e privadas do ensino fundamental. Fisioterapia em Movimento, 2017; $24: 2$.

5. BORGES LCDC, et al. Dores osteomusculares em professores do ensino fundamental e médio da cidade de Edéia, Goiás, Brasil. Referências em Saúde da Faculdade Estácio de Sá de Goiás-RRS-FESGO, 2019; 2(2).

6. BOSI PL. Fisioterapia preventiva na avaliação ergonômica de um escritório. Fisioterapia Brasil, 2018; 7(5): 363-366.

7. CALIXTO MF, et al. Prevalência de sintomas osteomusculares e suas relações com o desempenho ocupacional entre professores do ensino médio público. Caderno Terapia Ocupacional, UFSCar, São Carlos, 2015; $23: 3$.

8. CAMPOS ALP, et al. Prevalência de sintomas osteomusculares em indivíduos ativos e sedentários. Fisioterapia Brasil, 2016; 13(3): 189-193.

9. DA ROCHA RER, et al. Sintomas osteomusculares e estresse não alteram a qualidade de vida de professores da educação básica. Fisioterapia e Pesquisa, 2017; 24(3): 259-266.

10. DA SILVA MAIA FE. Fisioterapia do trabalho, uma conquista para a fisioterapia e a saúde do trabalhador: uma revisão de literatura. Revista Urutágua, 2014; 30: 124-132.

11. DE SOUSA MNA, DE ANDRADE M. Estresse e fadiga entre trabalhadores da limpeza urbana. Arquivos de Ciências da Saúde, 2017; 24(1): 59-64.

12. DE WALSH IAP, et al. Fisioterapia e saúde do trabalhador no brasil. Cadernos de educação, saúde e fisioterapia, 2018; 5(9): 69-80.

13. FERNANDES $\mathrm{MH}$, et al. Impacto da sintomatologia osteomuscular na qualidade de vida de professores. Revista brasileira de epidemiologia, 2011; 14: 276-284.

14. FERNANDES GCPS. Correlação Entre Sintomas Osteomusculares e Qualidade de Vida de Professores do Ensino Fundamental. 2ª Edição. Goiânia, 2018.

15. FERNANDES CS, et al. Distúrbios osteomusculares relacionados ao trabalho autorreferidos por profissionais de saúde de um hospital em Portugal. Revista Brasileira de Medicina do Trabalho, 2018; 16(3): 353-359.

16. FERREIRA LL, et al. Intervenção fisioterapêutica na prevenção das DORTS em auxiliares de limpeza. Revista Pesquisa em Fisioterapia, 2013; 3(1).

17. GRANJA CF, et al. "Avaliação dos Sintomas Osteomusculares em Professores Universitários." Revista Inspirar: movimento e saúde, $2014 ; 4$.

18. LEITE FEP, CARVALHO F. Causas de Afastamento Entre Professores do Ensino Fundamental da Rede. $2^{\underline{a}}$ Edição. Boa Vista, 2015.

19. LIMA JÚNIOR JP, SILVA TFA. Análise da sintomatologia de distúrbios osteomusculares em docentes da Universidade de Pernambuco-Campus Petrolina. Revista Dor, 2014; 15(4): 276-280. 
20. LIMA TBW, et al. Prevalência de sintomas osteomusculares e qualidade de vida de trabalhadores técnicos administrativos. Revista Brasileira Medicina Trabalho, 2020; 45-50.

21. MEIRA CJ, et al. A ergonomia e a atividade docente: perspectivas e desafios atuais. Revista Interdisciplinar Sulear, 2018.

22. MANGO MSM, et al. Análise dos sintomas osteomusculares de professores do ensino fundamental em Matinhos (PR). Fisioterapia em movimento, 2012; 25: 4.

23. NICOLETTI S. LER/DORT. Centro Brasileiro de Ortopedia Ocupacional-CBOO. Departamento de Ortopedia e Traumatologia da UNIFESP, 2017.

24. PICCOLI JCJ, SEGHETTO A. Nível de atividade física, prevalência de desconforto e dor muscular e capacidade de trabalho: uma avaliação no setor de call center de um banco de porto alegre, RS. Revista Brasileira de Ciência e Movimento, 2012; 20(3): 105-117.

25. SANTOS A. Uma reflexão sobre a profissão docente no Brasil, a partir dos cinco tipos de desvalorização do professor Sapere Aude, Belo Horizonte, 2015; 6(11): 349-358.

26. SILVA CC, NEVES MDS. Prevalência de queixas de sintomas osteomusculares em docentes: uma revisão de literatura. 2018.

27. SILVA EB, et al. Análise Funcional com Enfoque Físico de Membros Superiores em Professores com Síndrome Dolorosa. Caderno Terapia Ocupacional UFSCAR, São Paulo, 2015; 23(4): 757-764.

28. SILVA JVC, et al. Prevalência de lesões nos ombros de docentes da rede de ensino público da cidade de Montes Claros-MG. Revista Eletrônica Acervo Saúde, 2019; 28: e912.

29. SILVA LPDS, MORSCH P. Os benefícios da fisioterapia nas doenças osteomusculares associadas ao trabalho. Revista Científica da Faculdade de Educação e Meio Ambiente - FAEMA, 2019.

30. SUDA EY, et al. Relação entre nível geral de saúde, dor musculoesquelética e síndrome de burnout em professores universitários. Fisioterapia Pesquisa online, 2011; 18: 3.

31. VALLE G, CAMPOS T. Doenças Ocupacionais em Professores de Escola de Ensino Infantil e de Estimulação Precoce no Distrito Federal. 1 ${ }^{a}$ Edição, 2017. Brasília: Independente. 